\title{
Collinearity analysis of allotetraploid Gossypium tomentosum and Gossypium darwinii
}

\author{
F. Liu ${ }^{1,2}$, Z.L. Zhou' ${ }^{2}$ C.Y. Wang ${ }^{2}$, Y.H. Wang ${ }^{2}$, X.Y. Cai ${ }^{2}$, X.X. Wang ${ }^{2}$, \\ K.B. Wang ${ }^{2}$ and Z.S. Zhang ${ }^{1}$ \\ ${ }^{1}$ College of Agronomy and Biotechnology, Southwest University, Chongqing, \\ China \\ ${ }^{2}$ State Key Laboratory of Cotton Biology/Cotton Research Institute, Chinese \\ Academy of Agricultural Sciences, Anyang, China \\ Corresponding authors: K.B. Wang / Z.S. Zhang \\ E-mail:wkbcri@163.com / zhangzs@swu.edu.cn
}

Genet. Mol. Res. 15 (3): gmr.15038391

Received January 7, 2016

Accepted March 11, 2016

Published August 5, 2016

DOI http://dx.doi.org/10.4238/gmr.15038391

Copyright $(2016$ The Authors. This is an open-access article distributed under the terms of the Creative Commons Attribution ShareAlike (CC BY-SA) 4.0 License.

\begin{abstract}
Gossypium tomentosum and $G$. darwinii are wild allotetraploid cotton species, characterized by many excellent traits, including fiber fineness, drought tolerance, and Fusarium and Verticillium wilt resistance. Based on the construction of $\mathrm{F}_{2}$ linkage groups of G. hirsutum x G. tomentosum and G. hirsutum x G. darwinii, two genetic linkage maps were compared. As a result, we found a total of seven inverted fragments on chr02, chr05, chr08, chr12, chr14, chr16, and chr25, and three translocated fragments on chr05, chr14, and chr26. In addition, comparison of the inverted and translocated fragments revealed that the orientation of four of seven markers in G. tomentosum were consistent with $G$. hirsutum or G. raimondii. The orientation of one of seven inverted markers of $G$. darwinii was consistent with G. hirsutum, and the orientation of one of three translocated markers of $G$. tomentosum was consistent with $G$. raimondii. These results
\end{abstract}


indicate that, in comparison to G. darwinii, G. tomentosum has a closer genetic relationship to G. hirsutum. These findings will be important for our understanding on the genome structure of $G$. tomentosum and G. darwinii, and set the scene for further in-depth genome research such as fine mapping, tagging genes of interest from wild relatives, and evolutionary study.

Key words: Cotton germplasm resource; Allotetraploid cotton; Gossypium tomentosum; Gossypium darwinii; Linearity relationship

\section{INTRODUCTION}

Cotton is a natural white fibrous agricultural product, which is of great economic importance as a raw material for the textile industry, and has a wide variety of uses in the paper industry, in home fixtures, medical supplies, chemicals, and oil (Ensminger et al., 1990). Cotton (Gossypium spp) is one of the most expansively grown species around the globe, and is grown in tropical and subtropical regions between the latitudes $36^{\circ} \mathrm{S}$ and $46^{\circ} \mathrm{N}$ (Reller and Gerstenberg, 1997) in more than 80 countries (Fryxell, 1979; Smith, 1995). The Gossypium genus consists of 50 species (Fryxell, 1992; Stewart, 1995; Ma et al., 2008), which includes five allotetraploid species $\left[2 \mathrm{n}=4 \mathrm{x}=52 ;(\mathrm{AD})_{1}\right.$ to $\left.(\mathrm{AD})_{5}\right]$ and 45 diploid species $(2 \mathrm{n}=2 \mathrm{x}=26$, A through $\mathrm{G}$ and K) (Fryxell, 1979; Stewart, 1995; Brubaker et al., 1999; Zhang et al., 2005). The evolution of domesticated cotton has involved various steps, which provide scientists with insight into the role of polyploidy in the diversification process and permit the investigation of unique traits. In addition, it can further help geneticists to utilize germplasm from wild relatives. Allopolyploids are a great tool that can be used to understand the evolutionary process of two diploid but different sized genomes that evolved simultaneously. Studies on the evolution and diversity of the Gossypium genus provide basic knowledge on the morphological diversity of the genus and plant biology, which can help in the better utilization of genetic resources (Wendel et al., 2009).

More than 30 genetic maps have already been published in cotton, and most of them are based on interspecific crosses of domesticated tetraploid species, namely G. hirsutum and G. barbadense (Jiang et al., 1998; Zhang et al., 2002; Nguyen et al., 2004; Rong et al., 2004; Guo et al., 2007; He et al., 2007; Lacape et al., 2003, 2009). Interspecific tetraploid genetic maps are useful for understanding genome structure and for exploring the genetic basis of important agronomic characters. In addition, they provide a basis for identifying new DNA markers for further high density maps (Guo et al., 2007; Zhang et al., 2008; Yu et al., 2011; Kalivas et al., 2011; Tu et al., 2014).

Wild cotton has long been used as a genetic resource to introduce new traits that increase the potential of cultivated cotton species (Stewart, 1995). Gossypium darwinii, a wild allotetraploid species with an (AD) $)_{5}$ genome, is closely related to Gossypium barbadense, but is quite different from the cultivated Gossypium hirsutum. It has many excellent traits, including finer fiber fineness, drought tolerance, and Fusarium and Verticillium wilt resistance. Gossypium tomentosum is endemic to Hawaiian Islands, and it has many unique agronomic traits such as insect-pest resistance, drought tolerance, salt tolerance, heat tolerance, nectarilessness, and lint color (Liu et al., 2015). Many genetic studies, such as those investigating genomic and genetic structure/organization, have been conducted on the two cultivated tetraploids, $G$. hirsutum and G. barbadense. However, very little is known about the genomic architecture,

Genetics and Molecular Research 15 (3): gmr.15038391 
gene transfer, or introgression of unique traits from the other three tetraploids.

In the present study, simple sequence repeat (SSR) genetic maps were developed from two $\mathrm{F}_{2}$ populations, G. hirsutum x G. tomentosum (Chen et al., 2015) and G. hirsutum x G. darwinii (Kashif et al., 2015). The linearity relationship was compared between the two genetic maps, which will serve as an indispensable genomic resource for genome structure study, comparative genomic analysis, fine mapping, and map-based gene cloning of important traits.

\section{MATERIAL AND METHODS}

A linkage map was reconstructed from two previously constructed maps (Chen et al., 2015; Kashif et al., 2015). SSR markers uniformly distributed on different chromosomes were selected and checked after downsizing. The JoinMap 4.0 software was used for linkage analysis and map construction. Kosambi mapping function was used to convert recombination frequencies into map distances (cM). The Mapchart 2.2 software was used to draw the genetic map.

Linkage map assignment was established by common markers, which were already anchored as previously described (Wang et al., 2012; Li et al., 2014, 2015; Zhang et al., 2015). Chromosomal nomenclature was used as described by Guo et al. (2008), i.e., SSR loci anchored on chromosome (chr) 1-13 were designated to the A sub-genome (At), whereas loci confined to chr 14-26 were designated to the $\mathrm{D}$ sub-genome (Dt).

\section{RESULTS}

Comparing the linear relationship of the two genetic linkage maps, we found that most SSR markers present were collinear between the two maps. Meanwhile, part of the non-linear relationship appeared on the individual chromosomes between the genetic linkage maps of $G$. hirsutum x G. tomentosum and G. hirsutum x G. darwinii, which include seven inverted and three translocated fragments (Figure 1A-J).

Seven inversions were found on seven different chromosomes between the genetic maps of G. tomentosum and G. darwinii. The first inversion was on chr02 (MON_COT043HAU2643-HAU0248-HAU2923), the second on chr05 (MON-DPL0384-TMB1586BNL2448), the third on chr08 (CGR6748-HAU0709-BNL3257), the fourth on chr12 (MON CGR5158-NAU943-BNL1673), the fifth on chr14 (NAU3691-MON_CGR5818-TMB1513), the sixth on chr16 (CM56-JESPR102-NAU3676-GH56), and the seventh on chr25 (MON CGR5665-NAU2388-BNL3103). Three translocations were found on three different chromosomes between the genetic maps of $G$. tomentosum and $G$. darwinii, respectively: on chr05 the NAU2001-NAU1200-NAU3569 fragment underwent a parallel translocation with the MUSB0592-NAU1127 fragment; on chr26, the MON-CGR5678-MON-DPL0391 fragment underwent a parallel translocation with the MON-CGR6318-MON-CGR5802 fragment; and on chr14, the TMB0803-NAU2987 fragment underwent a parallel translocation with the MON_C2_0079-HAU0551 fragment.

Referring to the published G. raimondii genome sequencing data $\left(\mathrm{D}_{5}\right.$, Wang et al., 2012) and the latest $G$. hirsutum genome sequencing data ( $\mathrm{AD}_{1}$, Zhang et al., 2015), we compared the inversions and translocations on the genetic linkage map with the physical position and arrangement on the corresponding genome chromosome. The result showed that, among the inversions, the fragment orientation of $G$. darwinii on chr05 is consistent with the physical direction of the G. raimondii $\left(\mathrm{D}_{5}\right)$ and G. hirsutum $\left(\mathrm{AD}_{1}\right)$ genome sequences.

Genetics and Molecular Research 15 (3): gmr.15038391 
F. Liu et al.

A

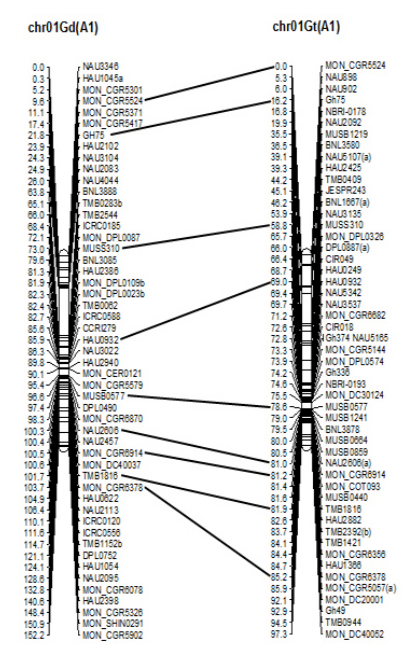

B

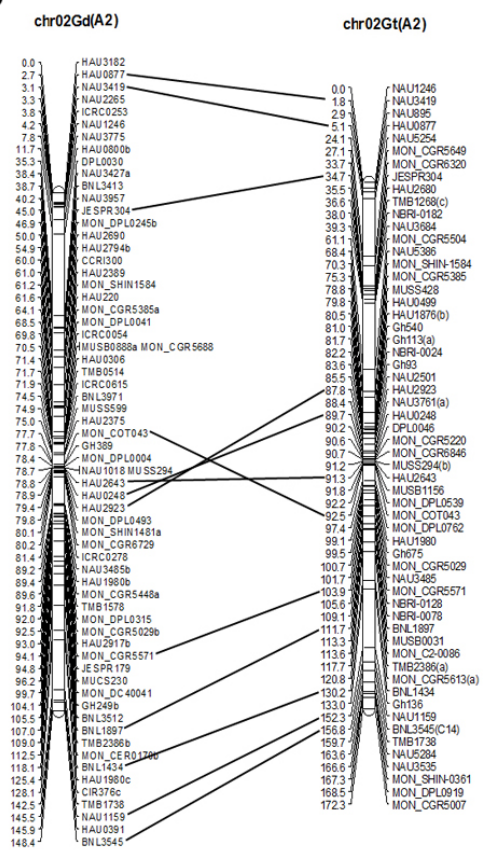

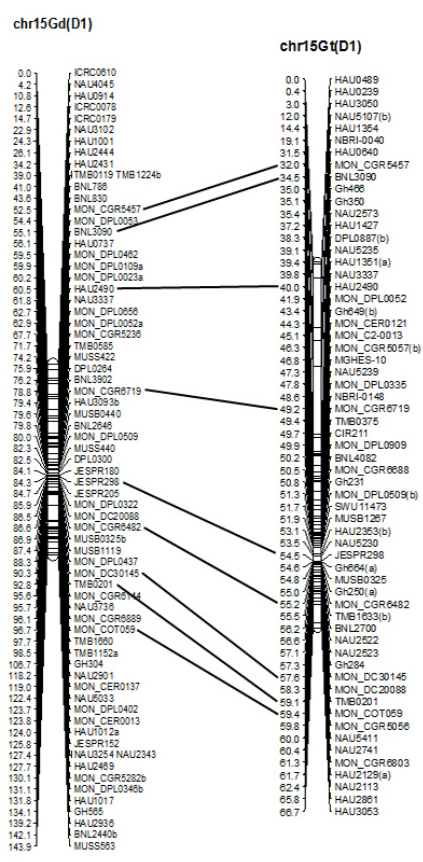

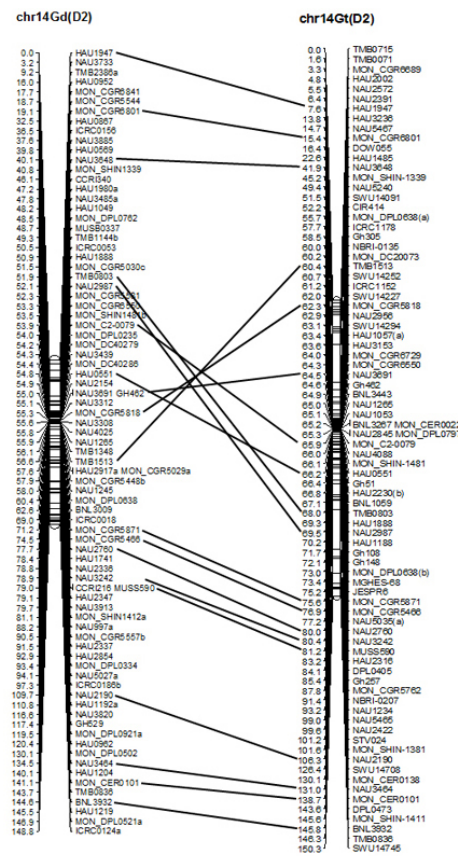

Figure 1. A.-J. Genetic map and collinearity comparison of Gossypium tomentosum (GT) and Gossypium darwinii (Gd). Chr01 to chr26 refer to the Chromsome from 01 to 26 , respectively. 
Figure 1. Continued.

C

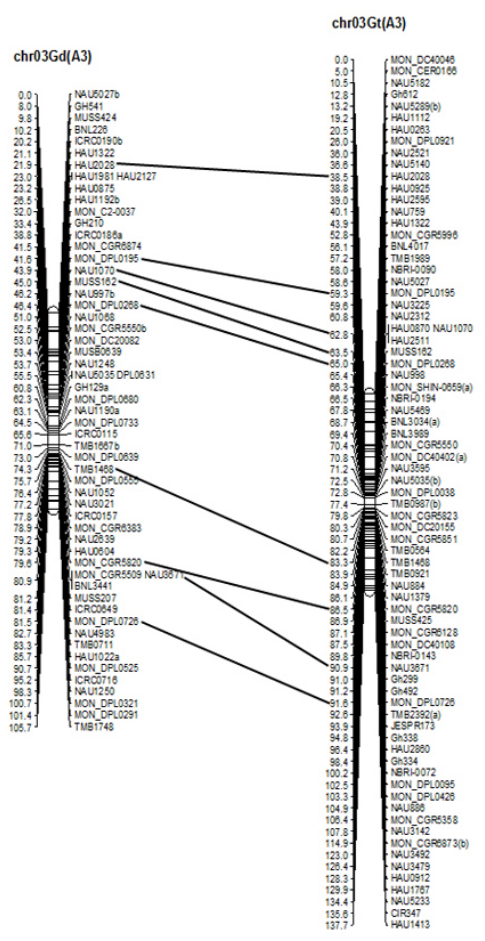

chr17Gd(D3)

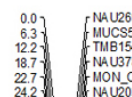

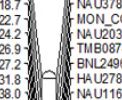

.47 - NaU2742

8.8
.8

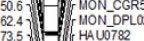

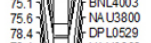

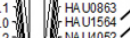

5.)

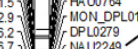

89.8.

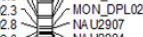

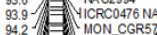

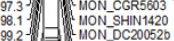

.1.)

A

6.

5 A 14 HoN-CGR682

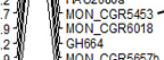

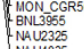

D
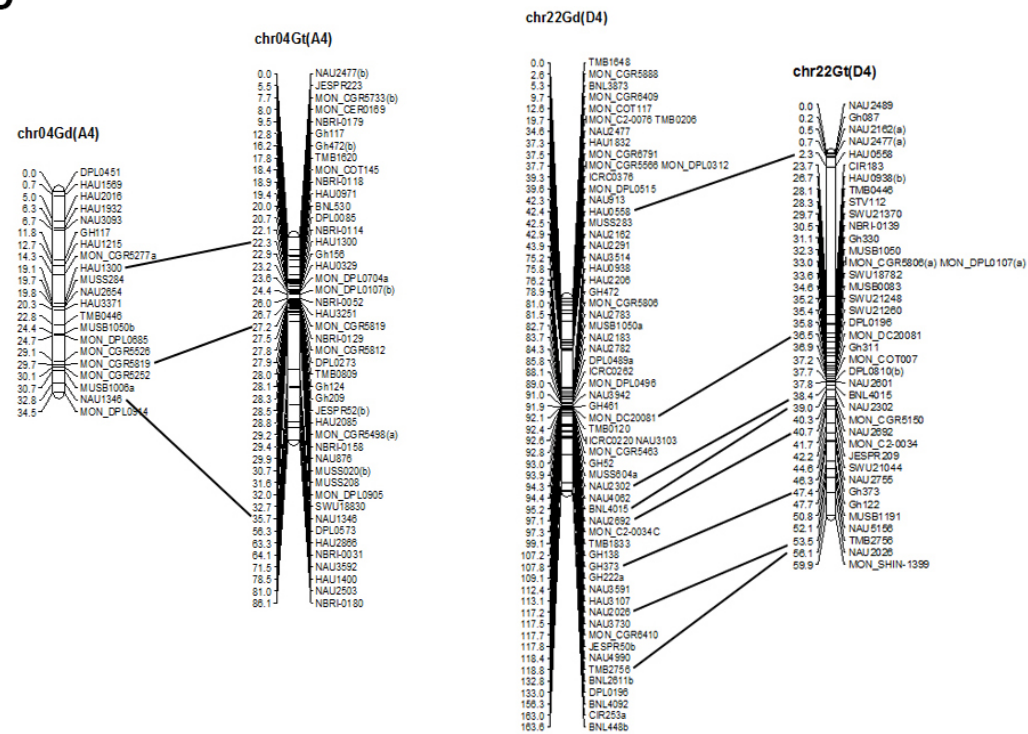

Continued on next page

Genetics and Molecular Research 15 (3): gmr.15038391 
F. Liu et al.

Figure 1. Continued.
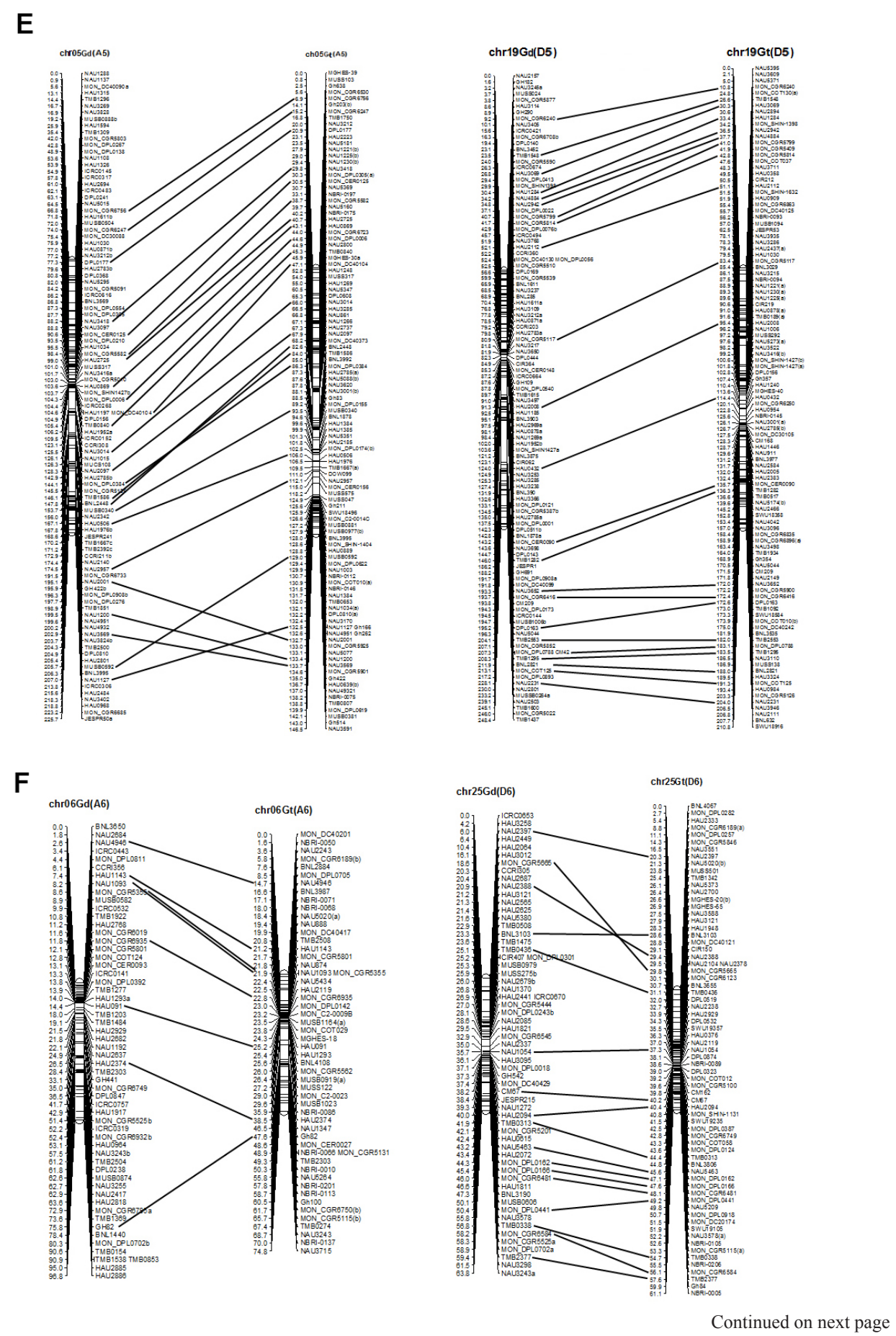

Genetics and Molecular Research 15 (3): gmr.15038391 
Figure 1. Continued.
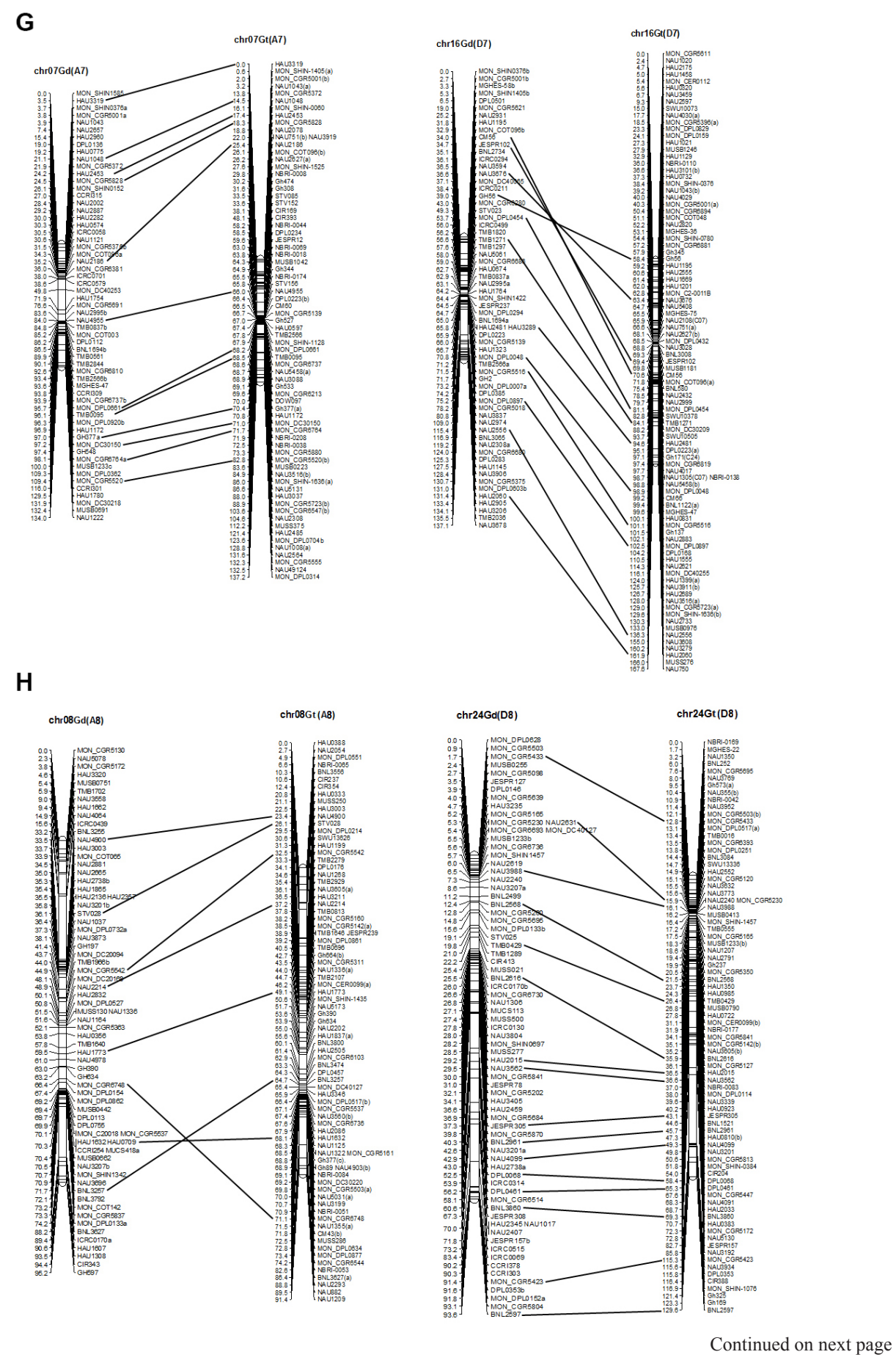

Genetics and Molecular Research 15 (3): gmr.15038391 
F. Liu et al.

Figure 1. Continued.
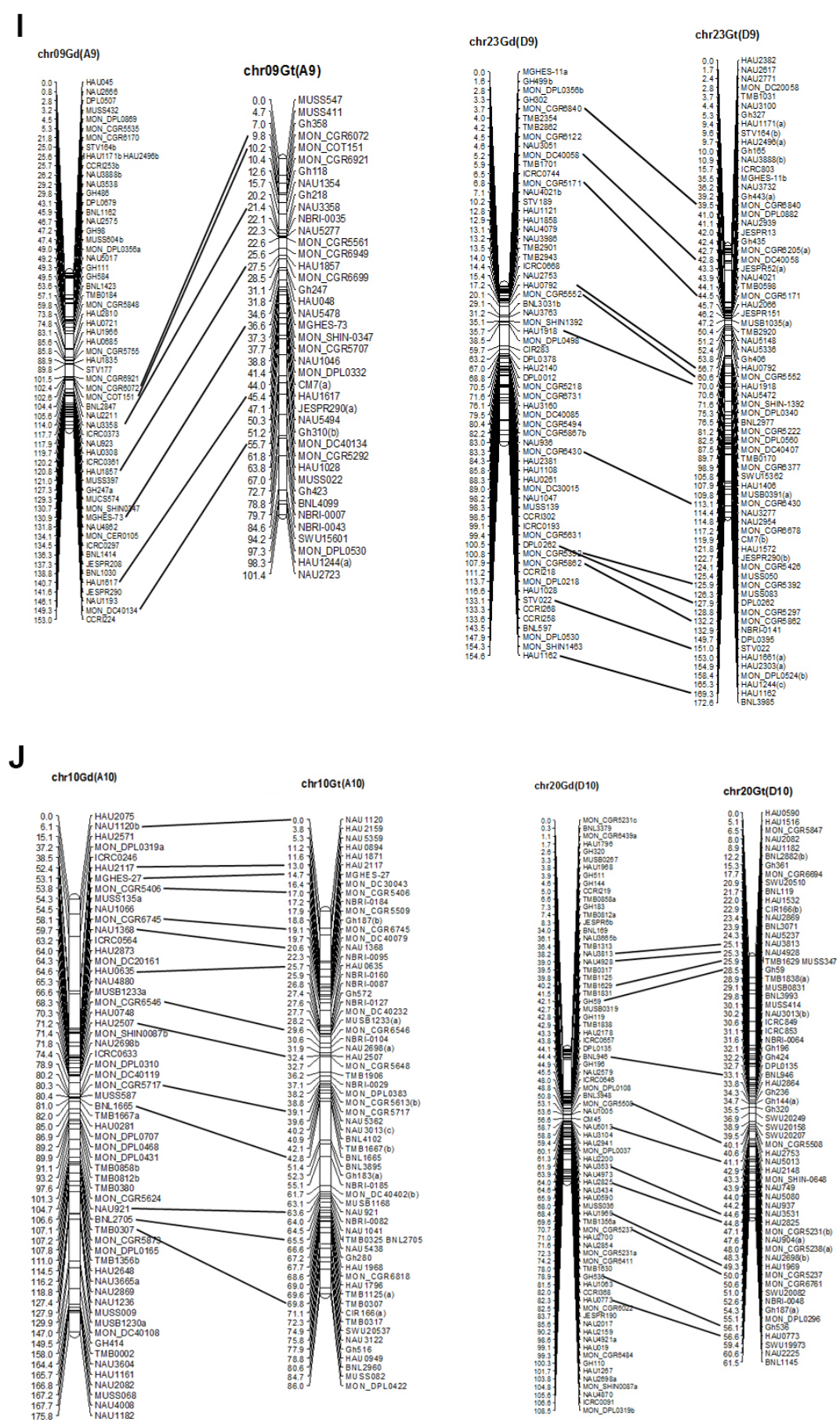

Genetics and Molecular Research 15 (3): gmr.15038391 
The fragment orientations of $G$. tomentosum on chr08, chr12, and chr25 are consistent with the physical directions of $G$. raimondii $\left(\mathrm{D}_{5}\right)$. The fragment orientations of $G$. tomentosum on chr08, chr12, and chr16 are consistent with the physical directions of G. hirsutum ( $\left.\mathrm{AD}_{1}\right)$. Among the translocation, just the fragment on chr26 corresponding physical position was found on G. raimondii $\left(\mathrm{D}_{5}\right)$ (Table 1).

Table 1. Comparison between the location of the genetic linkage fraction and the genome physical position.

\begin{tabular}{|c|c|c|c|c|c|c|}
\hline $\begin{array}{l}\text { Linkage } \\
\text { group }\end{array}$ & Markers & $\begin{array}{l}\text { Location on } G . \\
\text { darwinii (genetic } \\
\text { position, cM) }\end{array}$ & $\begin{array}{l}\text { Location on } G \text {. } \\
\text { tomentosum }(\text { genetic } \\
\text { position, } \mathrm{cM})\end{array}$ & $\begin{array}{l}\text { Corresponding } \\
\text { location on } G \text {. } \\
\text { raimondii }(\text { physical } \\
\text { position, } \mathrm{Mb} \text { ) }\end{array}$ & $\begin{array}{l}\text { Correspondin } \\
\text { g location on } \\
\text { G. hirsutium } \\
\text { (physical } \\
\text { position, Mb) }\end{array}$ & Events \\
\hline chr02 & $\begin{array}{l}\text { MON_COT043-HAU2643- } \\
\text { HAU0248-HAU2923 }\end{array}$ & $\begin{array}{c}\text { 77.7-78.8-78.9- } \\
79.4 \\
\end{array}$ & $92.5-91.3-89.7-87.8$ & & & Inversion \\
\hline chr05 & $\begin{array}{l}\text { MON_DPL0384-TMB1586- } \\
\text { BNL2448 }\end{array}$ & $144.1-146.1-147.8$ & $86.3-84-82.6$ & $21.4-21.6$ & $37.2-58.2$ & Inversion \\
\hline chr08 & $\begin{array}{l}\text { MON_CGR6748-HAU1632- } \\
\text { BNL3257 }\end{array}$ & $66.4-70.3-71.7$ & $71.1-68.1-64.7$ & $6.5-31.3-46.1$ & $85.6-58.9$ & Inversion \\
\hline chr12 & $\begin{array}{l}\text { MON_CGR5158-NAU943- } \\
\text { BNL1673 }\end{array}$ & $107.3-108-111$ & $111.2-109.2-107.1$ & $44.2-42.6$ & $93.5-41.7$ & Inversion \\
\hline chr16 & $\begin{array}{l}\text { CM56-JESPR102-NAU3676- } \\
\text { GH56 }\end{array}$ & $34-34.7-36.6-39$ & 70.6-69.4-63.4-58.4 & & $47.1-39.5$ & Inversion \\
\hline chr25 & $\begin{array}{l}\text { MON_CGR5665-NAU2388- } \\
\text { BNL3103 }\end{array}$ & $18.6-20.9-23.3$ & $29.8-29.4-28.6$ & $42.9-40.6$ & & Inversion \\
\hline chr05 & $\begin{array}{l}\text { NAU2001-NAU1200-NAU3569- } \\
\text { MUSB0592-NAU1127 }\end{array}$ & $\begin{array}{c}195.1-199.5- \\
202.9-205.7-207 \\
\end{array}$ & $\begin{array}{c}132.7-133.4-133.7- \\
129-132.5 \\
\end{array}$ & & & Translocation \\
\hline chr26 & $\begin{array}{l}\text { MON_CGR5678- } \\
\text { MON_DPL0391- } \\
\text { MON_CGR6318- } \\
\text { MON_CGR5802 } \\
\end{array}$ & $\begin{array}{c}34.9-35.3-37.4- \\
38.2\end{array}$ & $31.5-33-29.6-30$ & $17.1-31.1-10.2-10.8$ & & Translocation \\
\hline chr14 & $\begin{array}{l}\text { TMB0803-NAU2987- } \\
\text { MON_C2_0079-HAU0551- } \\
\text { NAU3691-MON_CGR5818- } \\
\text { TMB1513 }\end{array}$ & $\begin{array}{c}51.9-52.1-53.9- \\
54.8-55-55.3- \\
56.6\end{array}$ & $\begin{array}{l}68-69.5-65.9-66.2- \\
64.5-62.3-60.4\end{array}$ & & & $\begin{array}{l}\text { Inversion and } \\
\text { translocation }\end{array}$ \\
\hline
\end{tabular}

\section{DISCUSSION}

\section{Reciprocal translocations and inversion}

In the construction of Gossypium genetic linkage maps, researchers have repeatedly found reciprocal translocations between homologous chromosomes (Rong et al., 2004; Wang et al., 2006; He et al., 2007; Yu et al., 2012). Very few studies have focused on different linear relationships between homologous chromosomes in cotton. In this study, using G. hirsutum, we constructed allotetraploid genetic linkage maps of G. hirsutum x G. tomentosum and $G$. hirsutum x G. darwinii. Analysis of linear relationships at homologous positions revealed seven inversions (on chr02, chr05, chr08, chr12, chr14, chr16, and chr25) and three translocations (on chr05, chr14, and chr26), which were found separately on the two genetic linkage maps. When comparing the locations of the inversions and translocations with the physical positions of $G$. hirsutum, we found the same pattern of inversions at the corresponding positions on chr02, chr05, chr12, and chr14 in G. hirsutum, consistent with the translocation on the corresponding position of chr05 in G. hirsutum. For the first time, we report an inversion on the homologous chromosome fragments of chr02 and chr14, and describe the translocations on chr05 and chr14. In this study, we also found an inversion and translocation on the same fragment, which indicates that this is an active genetic region. At present, we are unable to explain the roles of the reciprocal translocation and inversion in the structural genes and geographical 
distribution of different cotton species. Further research is needed to confirm whether the inversion occurred before or after the translocation.

\section{Genetic mapping coupled with physical alignment of the genome}

A lot of previous research has focused on the origin and evolution of allotetraploid cotton. Findings reported by Fryxell (1992) and Wendel et al. (2009) support the idea that $G$. tomentosum and G. hirsutum have a close relationship, similarly G. darwinii and G. barbadense also have a close relationship. Limited research has been performed to determine the linear relationship of the chromosome genetic linkage between G. tomentosum and G. darwinii. Following the sequencing of the cotton genome, studying the relationship between the genetic linkage map and the physical map became feasible and convenient. Using the $\mathrm{F}_{2}$ population derived from interspecific crosses, we constructed two linkage maps of allotetraploid cotton $G$. hirsutum x G. tomentosum and $G$. hirsutum x $G$. darwinii separately. By referring to the latest published G. hirsutum genome sequencing data (Zhang et al., 2015), the linear relationship between the two wild allotetraploid cotton genetic linkage maps was compared based on genome-wide SSR markers. The results show that there is a good linear relationship between the genetic linkage maps of G. hirsutum x G. tomentosum and those of G. hirsutum $\mathrm{x}$ G. darwinii. Furthermore, part of the non-linear relationship appeared on the individual chromosomes between the two genetic linkage maps, including seven inverted and three translocated fragments. Compared with the sequence data for G. hirsutum (Zhang et al., 2015), we noted that among the seven inverted fragments, the orientation of just one marker (chr05), which comes from $G$. darwinii, is consistent with the physical arrangement on G. hirsutum, while the orientations of four markers (chr08, chr12, chr16, and chr25), which derive from $G$. tomentosum, are consistent with the physical position of G. hirsutum or G. raimondii. Among the three translocated fragments, the orientation of one marker (chr26), which comes from G. tomentosum, is consistent with the physical arrangement of G. raimondii. These results indicate that, in comparison to $G$. darwinii, G. tomentosum has a closer genetic relationship with G. hirsutum.

\section{Conflicts of interests}

The authors declare no conflict of interests.

\section{ACKNOWLEDGMENTS}

Research supported by the National Science and Technology Support Plan of China (\#2013AA102601) and the National Key Technology Support Program of China (\#2013BAD01B03).

\section{REFERENCES}

\footnotetext{
Brubaker CL, Bourland FM and Wendel JF (1999). The origin and domestication of cotton. In: Cotton: Origin, history, technology and production (Smith W and Cothren T, eds.). John Wiley \& Sons, Inc., 3-31.

Chen H, Khan MK, Zhou Z, Wang X, et al. (2015). A high-density SSR genetic map constructed from a F2 population of Gossypium hirsutum and Gossypium darwinii. Gene 574: 273-286. http://dx.doi.org/10.1016/j.gene.2015.08.022

Ensminger ME, Oldfield JE and Heinemann WW (1990). Excerpts with reference to cottonseed components. Ensminger Publishing Company, USA.
}

Genetics and Molecular Research 15 (3): gmr.15038391 
Fryxell PA (1979). The natural history of the cotton tribe. Texas A\&M University.

Fryxell PA (1992). A revised taxonomic interpretation of Gossypium L. Malvaceae. Rheedea 2: 108-165.

Guo W, Cai C, Wang C, Han Z, et al. (2007). A microsatellite-based, gene-rich linkage map reveals genome structure, function and evolution in Gossypium. Genetics 176: 527-541.http://dx.doi.org/10.1534/genetics.107.070375

Guo W, Cai C, Wang C, Zhao L, et al. (2008). A preliminary analysis of genome structure and composition in Gossypium hirsutum. BMC Genomics 9: 314. http://dx.doi.org/10.1186/1471-2164-9-314

He DH, Lin ZX, Zhang XL, Nie YC, et al. (2007). QTL mapping for economic traits based on a dense genetic map of cotton with PCR-based markers using the interspecific cross of Gossypium hirsutum x Gossypium barbadense. Euphytica 153: 181-197. http://dx.doi.org/10.1007/s10681-006-9254-9

Jiang C, Wright RJ, El-Zik KM and Paterson AH (1998). Polyploid formation created unique avenues for response to selection in Gossypium (cotton). Proc. Natl. Acad. Sci. USA 95: 4419-4424.http://dx.doi.org/10.1073/pnas.95.8.4419

Kalivas A, Xanthopoulos F, Kehagia O and Tsaftaris AS (2011). Agronomic characterization, genetic diversity and association analysis of cotton cultivars using simple sequence repeat molecular markers. Genet. Mol. Res. 10: 208217.http://dx.doi.org/10.4238/vol10-1gmr998

Kashif RK, Zhou ZL, Chen HD, Wang XX, et al. (2015). Genome wide SSR high density genetic map construction from an interspecific cross of G. hirsutum x G. tomentosum. Front. Plant Sci., in press.

Lacape JM, Nguyen TB, Thibivilliers S, Bojinov B, et al. (2003). A combined RFLP-SSR-AFLP map of tetraploid cotton based on a Gossypium hirsutum x Gossypium barbadense backcross population. Genome 46: 612-626. http://dx.doi. org $/ 10.1139 / \mathrm{g} 03-050$

Lacape JM, Jacobs J, Arioli T, Derijcker R, et al. (2009). A new interspecific, Gossypium hirsutum x G. barbadense, RIL population: towards a unified consensus linkage map of tetraploid cotton. Theor. Appl. Genet. 119: 281-292. http:// dx.doi.org/10.1007/s00122-009-1037-y

Li F, Fan G, Lu C, Xiao G, et al. (2015). Genome sequence of cultivated Upland cotton (Gossypium hirsutum TM-1) provides insights into genome evolution. Nat. Biotechnol. 33: 524-530. http://dx.doi.org/10.1038/nbt.3208

Li FG, Fan GY, Wang KB, Sun FM, et al. (2014). Genome sequence of the cultivated cotton Gossypium arboretum. Nat. Genet. 46: 467-572. http://dx.doi.org/10.1038/ng.2987

Liu F, Wang YH, Gao HY, Wang CY, et al. (2015). Construction and characterization of a bacterial artificial chromosome library for the allotetraploid Gossypium tomentosum. Genet. Mol. Res. 14: 16975-16980. http://dx.doi. org/10.4238/2015.December. 15.3

Ma XX, Zhou BL, Lü YH, Guo WZ, et al. (2008). Simple sequence repeat genetic linkage maps of A-genome diploid cotton (Gossypium arboreum). J. Integr. Plant Biol. 50: 491-502.http://dx.doi.org/10.1111/j.1744-7909.2008.00636.x

Nguyen TB, Giband M, Brottier P, Risterucci AM, et al. (2004). Wide coverage of the tetraploid cotton genome using newly developed microsatellite markers. Theor. Appl. Genet. 109: 167-175. http://dx.doi.org/10.1007/s00122-004$\underline{1612-1}$

Reller A and Gerstenberg J (1997). White gold, where do you go? Status quo and prospects of cotton usage. Gaia 1:35-51.

Rong J, Abbey C, Bowers JE, Brubaker CL, et al. (2004). A 3347-locus genetic recombination map of sequence-tagged sites reveals features of genome organization, transmission and evolution of cotton (Gossypium). Genetics 166: 389417. http://dx.doi.org/10.1534/genetics.166.1.389

Smith CW (1995). Cotton (Gossypium hirsutum L.). Chapter 6. In: Crop Production: Evolution, History, and Technology. John Wiley and Sons, Inc., New York, 287-349.

Stewart JM (1995). Potential for crop improvement with exotic germplasm and genetic engineering. In: G. Constable, Forrester N W. Challenging the future. Proceedings of the World Cotton Research Conference-1 Melbourne, Australia, CSIRO. 313-327.

Tu JL, Zhang MJ, Wang XQ, Zhang XL, et al. (2014). Genetic dissection of upland cotton (Gossypium hirsutum) cultivars developed in Hubei Province by mapped SSRs. Genet. Mol. Res. 13: 782-790. http://dx.doi.org/10.4238/2014. January. 31.4

Wang K, Song X, Han Z, Guo W, et al. (2006). Complete assignment of the chromosomes of Gossypium hirsutum L. by translocation and fluorescence in situ hybridization mapping. Theor. Appl. Genet. 113: 73-80. http://dx.doi. org/10.1007/s00122-006-0273-7

Wang K, Wang Z, Li F, Ye W, et al. (2012). The draft genome of a diploid cotton Gossypium raimondii. Nat. Genet. 44: 1098-1103.http://dx.doi.org/10.1038/ng.2371

Wendel JF, Brubaker C, Alvarez I, Cronn R, et al. (2009). Plant Genetics and Genomics: Crops and Models, Genetics and Genomics of Cotton: Evolution and Natural History of the Cotton Genus. Springer Science Business Media. LLC 3: 3-22.

Yu JZ, Kohel RJ, Fang DD, Cho J, et al. (2012). A high-density simple sequence repeat and single nucleotide polymorphism genetic map of the tetraploid cotton genome. G3 (Bethesda) 2: 43-58. http://dx.doi.org/10.1534/g3.111.001552

Genetics and Molecular Research 15 (3): gmr.15038391 
F. Liu et al.

Yu Y, Yuan D, Liang S, Li X, et al. (2011). Genome structure of cotton revealed by a genome-wide SSR genetic map constructed from a BC1 population between gossypium hirsutum and G. barbadense. BMC Genomics 12: 15. http:// dx.doi.org/10.1186/1471-2164-12-15

Zhang J, Guo W and Zhang T (2002). Molecular linkage map of allotetraploid cotton (Gossypium hirsutum L. x Gossypium barbadense L.) with a haploid population. Theor. Appl. Genet. 105: 1166-1174. http://dx.doi.org/10.1007/s00122002-1100-4

Zhang J, Lu Y and Yu S (2005). Cleaved AFLP (cAFLP), a modified amplified fragment length polymorphism analysis for cotton. Theor. Appl. Genet. 111: 1385-1395. http://dx.doi.org/10.1007/s00122-005-0070-8

Zhang T, Hu Y, Jiang W, Fang L, et al. (2015). Sequencing of allotetraploid cotton (Gossypium hirsutum L. acc. TM-1) provides a resource for fiber improvement. Nat. Biotechnol. 33: 531-537.http://dx.doi.org/10.1038/nbt.3207

Zhang Y, Lin Z, Xia Q, Zhang M, et al. (2008). Characteristics and analysis of simple sequence repeats in the cotton genome based on a linkage map constructed from a BC ${ }_{1}$ population between Gossypium hirsutum and G. barbadense. Genome 51: 534-546. http://dx.doi.org/10.1139/G08-033

Genetics and Molecular Research 15 (3): gmr.15038391 